\title{
The Possibility Proof is Not What Remains from Kant's Beweisgrund
}

\author{
MICHAEL OBERST \\ Humboldt University of Berlin \\ Email: mioberst@gmx.de
}

\begin{abstract}
The so-called 'possibility proof' in Kant's pre-Critical Beweisgrund has been widely discussed in the literature, and it is a common view that he never really abandoned it. As I shall argue, this reading is mistaken. I aim to show that the natural illusion in the Critique of Pure Reason, which is usually taken to be the possibility proof turned into a transcendental illusion, has both a different conclusion and a different argument than the possibility proof. Rather, what remains from Beweisgrund is what I will call the 'proof a posteriori', which the Critique turns into a transcendental illusion that is of regulative use for reason.
\end{abstract}

Keywords: rational theology, transcendental ideal, regulative use of reason

\section{Introduction}

Kant is famous for rejecting all attempts at proving the existence of God. In I762, however, the younger Kant proposed such a proof himself in The Only Possible Ground of Proof for a Demonstration of the Existence of God (or Beweisgrund, for short). This so-called 'possibility proof' has recently received meticulous scrutiny and is, I think, quite well-understood by now. In brief, Kant argues that all possibility must be grounded in an absolutely necessary being and then identifies this

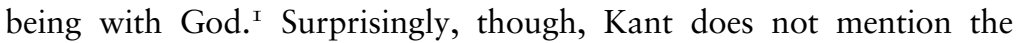
possibility proof in his refutation of the three possible proofs of God's existence in the Ideal chapter of the Critique (see A591/B6I9, A630/ B658). Even more confusingly, Kant now uses the designation 'the only possible ground of proof' to refer to the ontological proof. ${ }^{2}$ Seemingly, the possibility proof just disappears. 
Notwithstanding this, there is a wide agreement in the literature that Kant does not really abandon the possibility proof in the Critique. ${ }^{3}$ For example, Fisher and Watkins write:

Since the content of all other concepts is derived from limiting the concept of the ens realissimum, all other possibilities are derived from this original possibility, that is, all possibilities are grounded in God. So, not only does Kant link the material ground of possibility and God, but he does so in a way that is fundamentally the same as he does in The Only Possible Argument. (Fisher and Watkins I998: 390)

A passage in a transcript of Kant's lectures on rational theology is often cited as evidence for this view. There, he is reported to have said about the possibility proof:

But even this proof is not apodictically certain; for it cannot establish the objective necessity of such an original being, but only the subjective necessity of assuming it. However, this proof can in no way be refuted, because it has its ground in the nature of human reason; for reason absolutely forces me to assume a being which is the ground of everything possible, because otherwise I could not cognize at all in what something is possible (worin etwas möglich sey). (Th-Pölitz, 28: I034) ${ }^{4}$

The transcript reads that the proof 'can in no way be refuted', which has been taken to mean that Kant basically still endorses the possibility proof. ${ }^{5}$ At the same time, however, he denies that the proof is 'apodictically certain' because it can only establish the 'subjective necessity of assuming' the original being. On a widely held view, Kant now thinks that the proof shows the subjective necessity of the idea of God as regards the regulative use of the transcendental ideal, albeit without taking God to exist. ${ }^{6}$ That is, the proof justifies the use of the idea of God, but only for the regulative use of reason with regard to the unity of experience.

Despite this seemingly strong evidence, one should not assign too much weight to students' notes; and I shall argue that there are reasons to be particularly suspicious in this case. If we want to discern Kant's considered view, we have to look not into the transcripts, but the Critique. This task is quite difficult, though, because many strands of arguments run together there. To my mind, there are four main threads that we need to disentangle, namely discussions of: 
(a) a legitimate concept of God as the ens realissimum who does not possess sensible reality, but nonetheless is the ground of possibility;

(b) an illegitimate concept of God as the sum total (Inbegriff) of sensible reality that stems from a 'natural illusion';

(c) an illegitimate 'natural course of human reason' (and the associated proofs) that seeks to establish the existence of God in the legitimate sense;

(d) a legitimate regulative use by reason of the legitimate idea of God that rests on the transcendental illusion that he is the ground of the order of the world.

Many readers fail to distinguish these threads, but keeping them separate is crucial. For I shall argue that what remains from Beweisgrund is not the possibility proof. What readers take to remain of it is only a transcendental illusion that suggests (b) a Spinozistic God. But there is another proof in Beweisgrund that is more influential in the Critique, yet has received far less scholarly attention: that is the 'proof a posteriori' (as I shall call it), the predecessor of the Critique's physico-theological proof. ${ }^{7}$ According to the proof a posteriori, we can cognize empirically that God exists and is the ground of the order and harmony of the world. Although Kant rejects the related physico-theological proof in the Critique as well (c), he holds at the same time that the latter gives rise to a necessary transcendental illusion that has a positive function for the regulative, albeit not constitutive use of reason in regard to the empirical world (d). So what remains from Beweisgrund is the proof a posteriori (albeit in a modified form), which is turned into a transcendental illusion that has a legitimate regulative use.

In what follows, I will first present the two proofs in Beweisgrund before I consider the four threads in the Ideal. It will turn out in the conclusion that the account from the Pölitz transcript differs markedly from the Critique. My hope is that this article contributes to a better understanding of the Ideal chapter. Unfortunately, textual limitations force me to restrict my discussion to issues that are central for the relation of Beweisgrund to the Critique. Hence, there are many aspects or texts that I cannot discuss in as much detail as I would like.

\section{The Possibility Proof and the Proof $A$ Posteriori in Beweisgrund}

In Beweisgrund, Kant discusses two proofs in detail. ${ }^{8}$ The first section of Beweisgrund is dedicated to what is known as the 'possibility proof'. In its most simple form, the proof, which runs from the sheer possibility of something to God's existence, can be summarized as follows: 
(1) Something is possible.

(2) If something is possible, then this possibility must be grounded in an absolutely necessary being.

(3) There is an absolutely necessary being that grounds all possibility.

(4) If there is an absolutely necessary being that grounds all possibility, this being is God.

(5) God exists.

So the possibility proof consists of two main steps: first, it argues for the existence of an absolutely necessary being as the ground of possibility, and then it shows that this being is God. The literature is full of discussion about potential problems of the proof and how they could be avoided, but this is not my business here. ${ }^{9}$ I can also abstract from the hotly debated topic how God grounds possibility. Yet, there is one point that is relevant for my purposes. Some proponents of the debate hold that the God of the possibility proof grounds all realities by instantiating them, which faces the threat of Spinozism, according to which (as Kant understood it) the world is God. ${ }^{\text {Io }}$ However, Kant holds that God contains the 'ultimate real ground of all other possibility' (OPA, 2: 83; cf. 2: 79, 85, 87) and argues that these worldly possibilities are not instantiated by God (2: $85-6)$. This rules out that God instantiates all possibilities and is, in effect, identical to the world. ${ }^{\text {II }}$

The second proof is the topic of the very lengthy second section of Beweisgrund, and Kant introduces this proof by way of concluding the first section: ${ }^{12}$

But if we, through a mature assessment of the essential properties of the things that we get acquainted with through experience, perceive unity in the manifold and harmony in the separated even in the necessary determinations of their internal possibility, then we will be able to infer back to a unified principle of all possibility through the way of cognition a posteriori and ultimately arrive at the same fundamental concept of absolutely necessary existence from which we initially departed through the way a priori. Now our intention shall be to see whether a necessary relation towards order and harmony is to be encountered even in the internal possibility of things, and in this immense manifold unity, so that we can judge from it whether the essences of things themselves reveal a supreme common ground. (OPA, 2: 92) 
The possibility proof is a priori because it derives the consequence of God's creation from his essence, by which he grounds them. The second proof, by contrast, is a posteriori because it derives God as the ground of the world from the consequences. ${ }^{13}$ Thus, I will call this proof the 'proof $a$ posteriori', which considers the great harmony in the essences of things ${ }^{\mathrm{I} 4}$ and concludes that they must be grounded in an absolutely necessary being. It is not really clear what logical form the proof a posteriori is supposed to have, but Kant says that in this proof 'both the existence and the properties of it $^{15}$ are immediately inferred' from experience (OPA, 2: I 56). Thus, I assume that the proof can be summarized as follows:

(1) The actual world has a unified principle of its possibility.

(2) If the world has a unified principle of possibility, God (the absolutely necessary ground of the unity of possibility) exists.

(3) God exists.

Premise (I) is primarily based on the order of geometry (OPA, 2: 95-6) and mechanics (2:99-100), insofar as the unity that we encounter there is 'itself grounded in the possibilities of things' (2: I 25), as opposed to an order that 'is considered contingent and originating from the choice of an intelligent being' (2: I24). The difference between these kinds of orders is central here. The second order is called 'moral' because this order is contingent and depends on God's choice. By contrast, the first order is 'non-moral' (unmoralisch); the order is grounded in the natures of things and not dependent on God's choice, but his essence (2: IOO). According to Kant, the moral order could at most prove the existence of a 'craftsman, but not of a creator of the world' (2: I 23); so the proof a posteriori must be based on the non-moral order (2: I 22-3, I 24-5). Kant criticizes traditional physico-theology (the branch of theology that tries to cognize God through his supposed works) for merely considering the moral order (2: I I 6-23) and advocates an improved method of physico-theology that seeks out the non-moral order of the world (2: I23-37).

As regards premise (2), Kant answers the question, 'Is this unity ... possible without dependency from a wise author?', by flatly responding, 'The formal [aspect] of such great and manifold regularity prohibits this' (2: I 25). So Kant does not give an elaborate answer to the question why the great harmony of the world must be grounded by God. However, he does not consider the proof a posteriori to be sound anyway. Although Kant contends that the proof is 'possible' and 'in every way worthy to be brought to proper perfection through united efforts' (2: I 59), he holds 
that the proof is 'incapable of mathematical certainty and precision' (2: I60). ${ }^{16}$ The reason is that 'we are not acquainted with all created things (alles Erschaffene)' (2: I60), from which follows that we do not know if the world really has a unified principle of possibility. Premise (I) is therefore uncertain, even if highly probable; and as a result, the whole proof is uncertain - not even considering premise (2), which may also be problematic.

Again, I do not intend to discuss the two proofs in detail; I only outline them for the sake of discussing their afterlife in the Critique. Let us now turn to the first of the four threads of thought that I presented in the introduction.

\section{The Procedure of Forming the Legitimate Concept of the Ens Realissimum}

In section two of the Ideal, Kant describes a procedure of forming the 'transcendental ideal', that is, the concept of God. As this procedure is described at length by other authors (with whom I generally agree), ${ }^{17}$ I only give a brief summary of it here. Every predicate is either positive or negative. Positive predicates are 'transcendental affirmations', whereas negative predicates are 'transcendental negations'. Whilst a transcendental affirmation 'expresses a being, and hence it is called reality (thinghood)', a transcendental negation 'signifies a mere lack' of reality

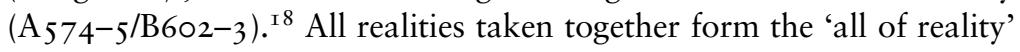
$(\mathrm{A} 575 / \mathrm{B} 603)$; and the being that instantiates all realities is the ens realissimum (A $576 / \mathrm{B} 604$ ), which is God. Thus, we attain the transcendental ideal (as the concept of God) by forming the concept that contains all transcendental affirmations.

However, Kant distinguishes between two conceptions of the ens realissimum:

The transcendental concept of God, as the ens realissimum, cannot be circumvented in philosophy ... The question now arises: am I to think of God as the sum total (complexus, aggregatum) of all realities, or as the supreme ground of them? (RPT, 8: 40on.)

Kant then rejects the first conception because it results in a selfcontradictory concept of God. ${ }^{19}$ As Kant argues in the Ideal, 'our whole sensibility, including all reality in appearance ... cannot belong to the idea of a highest being as an ingredient' (A $579 / \mathrm{B} 607) .{ }^{20}$ Rather, 
'the highest reality would ground the possibility of all things as a ground and not as a sum total' (A 579/B607). ${ }^{2 \mathrm{I}}$ I can only give a sketch of Kant's argument here. God is not only the ens realissimum, but also the 'original being' (ens originarium), that is, the 'origin of all things' (PM, 20: $30 \mathrm{I}$ ). If the original being instantiated all realities, including sensible ones, 'then the original being would be regarded as a mere aggregate of derivative beings', which is 'impossible' ( $\left.\mathrm{A}_{579} / \mathrm{B}_{607}\right)$. If we conceive of the ens realissimum as a sum total of reality, we end at Spinozism. ${ }^{22}$ Thus, this conception of God is inconsistent and hence illegitimate.

According to the legitimate conception, on the contrary, the ens realissimum instantiates only so-called 'pure' realities and is the ground of all limited realities, just as in Beweisgrund. For having a reality is not a matter of an either-or. Rather, there are degrees of reality (they have an 'intensive magnitude', B207). Kant thinks that only God possesses 'pure' realities, that is, realities of the highest degree. ${ }^{23}$ All realities of things in space and time, on the contrary, are not pure, but limited: 'there is no thing in the whole world that has pure reality' (Th-Pölitz, 28: IO2I). ${ }^{24}$ The notion of an ens realissimum as the sum total of all pure realities (and the ground of all others) is consistent, according to Kant, because pure realities cannot contradict each other. ${ }^{25}$ So it is only this conception that can legitimately be the object of belief or of proofs of God's existence.

It is not uncommon to read the formation of the transcendental ideal as a process that occurs by virtue of a natural illusion. ${ }^{26}$ But this strikes me as false. For the discussion of the formation of the transcendental ideal is already completed when Kant first uses the word 'illusion' (at $\mathrm{A}_{5} 8 \mathrm{I} / \mathrm{B} 609$ ). Consequently, we should assume that the legitimate concept of God as the ground of possibility is formed independently of an illusion. As we shall see in section 5 , there is nonetheless an illusion attached to this idea as well. But now let us turn to the infamously complex and difficult illusion that Kant describes at the end of section two of the Ideal. I will argue that this illusion only concerns the illegitimate conception of God.

\section{The Natural Illusion Leading to the Illegitimate Conception of the Ens Realissimum}

The second section of the Ideal not only provides a procedure by which the legitimate concept of God can be formed, but also deals with a natural illusion that arises from our subjective needs as regards the formation of concepts. These two issues are deeply interwoven. According to Kant, the 'principle of thoroughgoing determination' (PTD) requires that 
'among all possible predicates of things, insofar as they are compared with their opposites, one must apply to it' (A 57 I-2/B599-600). Since Kant later in the text clarifies that he is talking about transcendental affirmations and negations, the PTD holds in fact that everything is completely determined with regard to each pair of transcendental affirmations and their negations. A concept of a thing that is determined with respect to all of these pairs is called a 'complete concept' ( $A_{572}$ / B600). ${ }^{27}$ The transcendental ideal, as the concept of the ens realissimum, represents the all of reality and is the sole complete concept that only has transcendental affirmations - this is how it is defined. But every complete concept of worldly things contains some transcendental affirmations along with some transcendental negations.

Now Kant holds that one can think the absence of reality only if one has a concept of this reality. For example, 'The person blind from birth cannot form the least representation of darkness, because he has no representation of light' $\left(\mathrm{A}_{575} / \mathrm{B}_{603}\right)$. This lends a crucial role to the idea of an 'all of reality' that is the sum of all transcendental affirmations. All other concepts are limitations of the all of reality because they contain negations of some reality that belong to the all of reality. For this reason, Kant metaphorically refers to the all of reality as 'the entire storehouse of material from which all possible predicates of things can be taken' (A $575 / \mathrm{B} 603)$. But he insists:

It goes without saying that with this aim - namely, solely that of representing the necessary thoroughgoing determination of things - reason does not presuppose the existence of a being conforming to the ideal, but only the idea of such a being, in order to derive from an unconditioned totality of thoroughgoing determination the conditioned totality, i.e., that of the limited. (A 577-8/B605-6)

What is noteworthy here is not only that this requirement of reason gives us no warrant for assuming God's existence, but also that the relation between the 'unconditioned totality' (the all of transcendental affirmations) and the 'conditioned totality' (the limited concepts) is one between concepts and not between things. This needs further explanation. The PTD demands of every possible reality that we are able to determine whether it belongs to a thing or not. For we can form a limited concept only by limiting an unlimited reality in thought; and if we assume that all unlimited realities can be limited, ${ }^{28}$ it follows that the legitimate concept of God (as the sum of all pure realities) must be possible if the totality of all 
limited concepts is to be possible. This does not mean that we must form the transcendental ideal before we can form limited concepts. Rather, it means that the possibility of the totality of all possible limited concepts presupposes the possibility of the totality of all possible unlimited concepts (that is, the transcendental ideal).

This is not a metaphysical grounding relation between God and the world, in the sense that God would ground possibility by instantiating the realities of worldly objects. Kant admits that his initial presentation of the relation between the all of reality and limited concepts suggests that this is the way God grounds possibility, but parenthetically remarks that this has only been the 'first crude outline' of the story (A 579/B607). For 'the derivation of all other possibility from this original being, strictly speaking, also cannot be regarded as a limitation of its highest reality and as a division, as it were, of it' (A $579 / \mathrm{B} 607)$. God is not the 'storehouse' who grounds possibility by offering the material for limitation, but the ground of possibility outside the world.

Yet Kant's revision of the 'first crude outline' affects not only the grounding relation between God and the world, but also the grounding relation between the transcendental ideal and limited concepts. For Kant now says that the 'manifoldness' of worldly things 'rests not on the limitation of the original being itself, but on its complete consequences' (A 579/B607). ${ }^{29}$ The 'complete consequences' of God are the world and everything that is possible through him (A $579 / \mathrm{B} 607)$. But this means that the 'entire storehouse' on which the limitation of concepts depends is the all of sensible $^{3 \circ}$ reality, not the all of pure reality that constitutes the legitimate concept of God. ${ }^{3 \mathrm{I}}$ As we shall see now, the all of sensible reality is at the heart of the infamous 'illusion' of reason $\left(\mathrm{A}_{5} 8 \mathrm{I} / \mathrm{B} 609\right)$ at the end of section two; and I shall argue that this illusion attempts to establish the existence of the ens realissimum in the flawed, Spinozistic sense.

Kant begins his discussion of the illusion by raising a question:

Therefore I ask: How does reason come to regard all the possibility of things as derived from a single possibility that lies at the bottom, namely that of the highest reality, and then to presuppose this ${ }^{32}$ as contained in a particular original being? (A58I/B609)

Crucially, the transcendental ideal (and the illusion attached to it) 'is grounded on a natural and not a merely arbitrary idea' (A $58 \mathrm{I} / \mathrm{B} 609$ ). 
As Grier has pointed out, reason has an interest in pursuing the totality of conditions, even though we cannot reach it in experience. Therefore, the transcendental ideas of the soul, the world and God are necessary illusions - they seem to be the unconditioned that reason demands (and this semblance is unavoidable), but it would be an error to judge that the unconditioned is, or even could be, given in experience. So we have to distinguish between transcendental illusions, which are unavoidable but are not judgements, and transcendental errors, which are motivated by illusions but avoidable. ${ }^{33}$

The illusion in section two turns on the PTD. ${ }^{34}$ For we can form the complete concept of a thing only if we compare it with all possible sensible realities (as shown above). Thus, we must possess the concepts of all sensible realities in order to decide whether a transcendental affirmation or its negation applies to a given thing. ${ }^{35}$ Since we can become acquainted with realities only by experience, ${ }^{36}$ these realities must 'be presupposed as given in one sum total' ( $\mathrm{A}_{5} 82$ /B6ro) as the enabling condition of the formation of sensible concepts. ${ }^{37}$ Thus, Kant thinks that the conditioned totality of sensible concepts presupposes as its condition that all the realities represented by positive sensible concepts are actually instantiated. But there is an illusion involved in the argument that Kant does not make explicit, namely the illusion that we can in fact determine a complete concept. ${ }^{38}$ While introducing the PTD at the beginning of section two, he remarks:

Thoroughgoing determination is consequently a concept that we can never exhibit in concreto in its totality, and thus it is grounded on an idea which has its seat solely in reason, which prescribes to the understanding the rule of its complete use. (A573/B60I)

Although the task for reason to form complete concepts cannot be fulfilled, the idea of a complete concept is a necessary illusion that serves as a regulative idea for the use of the understanding. Unfortunately, Kant does not say why this goal is unachievable. But as we have seen, it is a necessary condition of forming complete concepts that the all of sensible reality is given in a sum total. Since Kant speaks of the 'idea of the sum total of all reality' $\left(\mathrm{A}_{5} 82 / \mathrm{B} 6 \mathrm{IO}\right)$ and ideas are concepts of reason that can have no corresponding object in experience $\left(\mathrm{A}_{320} / \mathrm{B}_{377}, \mathrm{~A}_{62} \mathrm{I} / \mathrm{B} 649\right)$, this suggests that Kant thinks that the all of sensible reality can never be given in experience. But since reason can only form a complete concept if the all of sensible reality is given, we are prone to the illusion that the latter is the case. 
However, this does not yet account for an illusion that God exists, which is only accomplished by a series of further illusions. First, we think that the sum total of the realities we can become acquainted with - that is, the sum total of sensible realities - is the sum total of realities in general. However, this is an illusion because the sum total of sensible realities does not include the noumenal realities of things in themselves, let alone the pure realities that are constitutive of the legitimate concept of God. ${ }^{39}$ And further illusions (that I do not need to discuss here) lead to mistaking this sum total of sensible realities for God $\left(\mathrm{A}_{5} 82-3 / \mathrm{B} 6\right.$ IO-II $)$. Hence, the illusory argument would establish not only that the all of sensible reality is grounded by God, but even that the all of these realities itself is God. This would establish Spinozism, which Kant condemns.

In conclusion, section two of the Ideal discusses four different grounding relations:

(i) the grounding relation by which the totality of the concepts of pure realities makes the totality of the concepts of limited realities possible;

(ii) the grounding relation by which the totality of positive sensible concepts makes the totality of sensible concepts possible;

(iii) the grounding relation by which the sum total of sensible realities makes the totality of sensible concepts possible;

(iv) the grounding relation by which God grounds worldly possibilities.

Relation (i) does not establish the existence of any object, but only the necessity of a particular concept; however, Kant ultimately sets this relation aside in favour of relation (ii) because sensible concepts are not limitations of pure realities. $4^{40}$ Relation (iii) figures in a transcendental illusion that we can actually determine the complete concept of a thing, but only further illusions make us identify the sum total of sensible realities with a Spinozistic God. Relation (iv) is only a by-product of Kant's discussion; he merely suggests that (iv) is part of the legitimate concept of God, and the transcendental illusion in section two does not involve this relation.

But if we look back to Beweisgrund, the possibility proof would establish (iv), but not the other grounding relations. Recall that this proof argues that there must be an absolutely necessary being that is the ground of worldly possibilities. This is an entirely different kind of grounding than grounding the possibility of concepts by providing the sensible material. Furthermore, while the God of the possibility proof is separate from the 
world, the God of the transcendental illusion is identical to the sensible world. Hence, it is not the case that the possibility proof is reincarnated in the form of the transcendental illusion in section two of the Ideal.

\section{The Natural Course of Reason that Attempts to Prove God's Existence}

Section three of the Ideal has received scant scholarly attention. The main reason may be that its function has been unclear. Indeed, it is not easy to see why section three is not somehow redundant. The title, 'On the grounds of proof of speculative reason for inferring the existence of a highest being' ( $\mathrm{A}_{5} 83$ / $\mathrm{B} 6 \mathrm{II}$ ), may suggest that the section just introduces and pre-summarizes the refutations of the ontological, cosmological and physico-theological proofs to come. On the other hand, since it deals with a 'natural course taken by every human reason' (A $584 / \mathrm{B} 6 \mathrm{I} 2$; cf. A586/B6I4, A590/B6I8), one might think that the third section extends the natural illusion Kant discussed in section two. ${ }^{4 \mathrm{I}}$ But none of this holds. On my view, section three introduces an illusion that is different and independently motivated from the illusion in section two. For the latter attempts to establish a flawed idea of God, whereas the former provides a flawed ground of proof for taking the legitimate idea of God to correspond to an actually existing being. Therefore, it is only the illusion in section three that gives rise to the three attempts at proving the existence of the ens realissimum in the legitimate sense.

Kant distinguishes the two illusions as follows:

In spite of its urgent need to presuppose something that the understanding could take as the complete ground for the thoroughgoing determination of its concepts, reason notices the ideal and merely fictive character of such a presupposition much too easily to allow itself to be persuaded by this alone straightway to assume a mere creature of its own thinking to be an actual being, were it not urged through something else to seek somewhere for a resting place in the regress from the conditioned, which is given, to the unconditioned ... $\left(\mathrm{A}_{5} 83-4 / \mathrm{B} 6 \mathrm{II}-\mathrm{I} 2\right)$

Kant does not consider the natural illusion in section two as a potential proof of God because, I take it, the idea of God as a sum total is selfcontradictory; a proof based on this idea would be a non-starter. In section three, however, Kant discusses a 'natural course' of thinking that, if successful, would prove the existence of God in the legitimate sense. The natural course is a series of two illusions. It begins with 
'common experience' and seeks for an 'absolutely necessary being' that grounds the conditioned beings in experience (A $584 / \mathrm{B} 6 \mathrm{I} 2)$. Then, by a further step, we have the illusion that this being is the ens realissimum, which makes us conclude that the 'being of the highest reality' is the most plausible candidate for the absolutely necessary being (A586/B6I4). ${ }^{42}$ Unsurprisingly, Kant thinks that this 'natural' way of proving the existence of God is mistaken (A $587-8 / \mathrm{B}_{6} \mathrm{I}_{5}-\mathrm{I} 6$ ), even though he credits it for having 'a certain cogency'.

By contrast, some readers hold that the series of illusions in sections two and three are different steps of one extended argument. On their view, it is precisely the failure of the argument from section two to establish a legitimate concept of God which gives rise to another illusion. ${ }^{43}$ However, there seems to be a dilemma for their position. Either the natural course is just an extension of the preceding illusion in section two, but then we would still be committed to the illusion that God is the sum total of sensible realities. ${ }^{44}$ Or God is not the sum total of realities, but then it is unclear why the illusions are not independent from each other. The obvious solution for this dilemma is to accept that these illusions are separate. ${ }^{45}$

What makes the natural course of reason relevant for the rest of the Ideal is that Kant apparently builds the classification of the proofs of God's existence on it:

All paths on which one may set forth with this aim either begin from determinate experience and the special constitution of our world of sense known through it, and ascend from that by means of laws of causality to the highest cause outside the world; or else they are empirically grounded on an experience that is only indeterminate, i.e., on some existence; or, finally, they abstract from all experience and infer the existence of a highest cause entirely a priori from mere concepts. The first proof is the physico-theological, the second the cosmological, and the third the ontological proof. There are no more of them, and there also cannot be any more. ... As to the order in which these species of proof have to be presented for examination, however, it will be just the reverse of that taken by reason in gradually unfolding itself, and in which we have first placed them. (A590-I/B6I 8-I9)

By speaking of 'reason in gradually unfolding itself', Kant plainly refers to the natural course of reason. The title of section three indicates that the 
section presents the 'grounds of proof' concerning the existence of God, which, in this context, means as much as a rough sketch of the argument(s). ${ }^{46}$ Arguably, the natural course of reason provides this ground of proof; and the three attempted proofs Kant aims to refute are motivated by the natural course. ${ }^{47}$ There is also an order in these proofs that corresponds to the natural course. For the physico-theological proof, which starts from experience, entails the cosmological proof, which in turn entails the ontological proof. Kant's argumentative strategy is to show that the ontological proof fails and then that the other proofs entail the ontological proof, so they fail, too (A606-7/B634-5, A 625/B653, A629-30/B657-8).

The physico-theological proof strongly resembles the proof a posteriori from Beweisgrund. We find a 'purposive order' in the world that is:

quite foreign to the things of the world, and pertains to them only contingently, i.e., the natures of different things could not by themselves agree in so many united means to determinate final aims, were they not quite properly chosen for and predisposed to it through a principle of rational order grounded on ideas. $(\mathrm{A} 625 / \mathrm{B} 653)^{48}$

Therefore, we conclude that there exists at least one being that possesses the great wisdom that is required to produce such an order. And because of the unity of this order there can only be one such being, namely God. 49 We can summarize the beginning of Kant's reconstruction of the physicotheological proof as follows:

(1) The actual world displays an order that is only possible if there is a 'wise cause' (A625/B653) that grounds this order. Call this a 'Wise Author'.

(2) There is at least one Wise Author.

(3) The unity of the world order reveals that there is only one Wise Author.

(4) There is exactly one Wise Author.

The physico-theological proof clearly corresponds to the natural course of reason: it begins by experience and seeks for an unconditioned ground of the order of nature. But so far the proof is incomplete: it has not yet shown that the Wise Author is an absolutely necessary being, let alone God. And Kant's refutation of the physico-theological proof is based on the claim that this gap cannot be bridged empirically. 
Unfortunately, the structure of the refutation is not very clear. In any case, Kant seems to reject two different arguments that depend on two different ways of conceiving of the Wise Author. These ways correspond to what Beweisgrund considered the bad and the improved method of physicotheology, respectively. The first argument makes an inference ... from the analogy between natural products and those of human art' (A626/B654). While Kant rejects this method, he holds that 'once we are supposed to name a cause, we could not proceed more securely than by analogy with such purposive productions, which are the only ones where we are fully acquainted with the causes and the way they act' (A626/B654). Yet this argument does not bring us very far. For it could:

prove merely the contingency of the form, but not of the matter, i.e., of substance, in the world; for the latter would further require that it be able to be proved that the things of the world would in themselves be unsuited for such an order and harmony according to universal laws if they were not in their substance the product of a highest wisdom. (A627-8/655-6)

Consequently, the proof 'could at most establish an architect of the world, who would always be very limited by the suitability of the material on which he works, but not a creator of the world' (A627/B655). A mere architect of the world could not be God because the architect has defects. In order to show that there is a creator, we have to prove 'the contingency of matter itself', and not only of the form in which nature is arranged (A627/B655). That matter is contingent means that it is dependent on a creator as its cause (A629/B657); and the Wise Author can only be God if he is the creator of matter, and hence of the world..$^{\circ}$ We thus need to find a way that keeps the physico-theological proof empirical (as intended), but avoids the trap of the analogy with human artefacts.

For this reason, Kant goes on to discuss the second argument that he rejects, which 'goes from the thoroughgoing order and purposiveness that is to be observed in the world, as a thoroughly contingent arrangement, to the existence of a cause proportioned to it' (A627/B655)..$^{\mathrm{I}}$ This argument apparently makes empirical inferences from the harmony in substances (and their essences and laws). Unlike the first argument, it does not conceive of the Wise Author by analogy with human craftsmen. Still, Kant argues that the argument must provide us with the concept of a being that has 'all perfection' (A628/B656). But what we could get by this method at most is the existence of a being with 'very great $\ldots$ power and excellence' $(\mathrm{A} 628 / \mathrm{B} 656)$ - make the world 
as great as you want, we can always assume that its cause is just a very powerful finite being, not the infinite being that possesses all reality. Hence, the only way to save the physico-theological proof is by appealing to the cosmological proof (A629/B657), so the former must proceed as follows:

(5) The Wise Author is the creator of the world.

(6) The creator of the world is the absolutely necessary being.

(7) The absolutely necessary being is God.

(8) God exists.

Therefore, we have to account for propositions (5)-(7), which, if at all, could only be accomplished by the cosmological proof. As a result, the physico-theological proof entails the cosmological proof and is not independent of it. This is the key difference between the physicotheological proof and the proof a posteriori from Beweisgrund - the latter gave no account of why a unified principle of possibility requires the existence of God, whereas the former acknowledges that this can only be accounted for by the cosmological proof. Otherwise, the proof a posteriori and the physico-theological proof are closely related, as they attempt to prove God by relying on an improved method of physicotheology. Common to both is also Kant's criticism of them: there is always a gap in the inference from the actual world to the most real being.

I do not further follow Kant's refutations because the cosmological and even more the ontological proof are widely discussed and wellunderstood. What makes the physico-theological proof interesting in particular is that Kant attributes a positive role to it. For he says that the proof 'enlivens the study of nature' and offers a 'guiding thread of a particular unity whose principle is outside nature' (A623/B65I). Kant discusses this positive function of the proof in the Appendix to the Transcendental Dialectic, to which we now turn.

\section{The Regulative Function of the Transcendental Ideal}

Despite the failure to prove God's existence, the transcendental ideal has an indispensable positive function for empirical cognition..$^{52}$ According to Kant, reason, in its real use, seeks for the unconditioned that is the condition of all conditioned beings; therefore, reason demands the existence of certain objects that are represented by 'transcendental ideas' (A334/B39I). However, no adequate object can be given to transcendental ideas in experience - to this extent, reason is 'dialectic' and of no 'constitutive' use because reason cannot establish the existence of 
the unconditioned (A338ff./B396ff.). Notwithstanding this, there is a 'regulative' use of reason, as Kant argues in the Appendix to the Transcendental Dialectic. That is, the principles of reason do not establish the existence of an object in experience, but only direct the use of the understanding with regard to experience. ${ }^{53}$ The transcendental ideas have a positive and indispensable role for the regulative use of reason because they ground a necessary illusion (namely, that the unconditioned exists in experience) and, as it were, a focus imaginarius which reason seeks to approximate as far as possible (A644-5/B672-3).

This is a vast topic, and I will not elaborate on it further. But the idea that God grounds the order and harmony of the world is such a necessary illusion that is of regulative use for reason:

Finally and thirdly, (in regard to theology) we have to consider everything that might ever belong to the context of possible experience as if this experience constituted an absolute unity, but one dependent through and through, and always still conditioned within the world of sense, yet at the same time as if the sum total of all appearances (the world of sense itself) had a single supreme and all-sufficient ground outside its range, namely an independent, original, and creative reason, as it were, in relation to which we direct every empirical use of our reason in its greatest extension as if the objects themselves had arisen from that original image of all reason. (A672-3/B700-I)

Apparently, the unity of experience is basically the same as the unity and harmony in essences that we are acquainted with from Beweisgrund. But now, Kant not only thinks that we cannot cognize the unity, but that it is even impossible that this unity can ever be realized in the world. Rather, the unity is an illusory task set by reason. For the 'systematic complete unity' of experience is an 'idea' (A677/B705); and since an idea is a non-empirical concept 'which goes beyond the possibility of experience' ( $\left.\mathrm{A}_{320} / \mathrm{B}_{377}\right)$, the systematic unity 'can never be presented adequately in experience' (A677/B705). ${ }^{54}$ Therefore, it is only an (albeit necessary) illusion that God is the ground of the assumed unity. ${ }^{55}$

So Kant presents two transcendental illusions in the Ideal that must be well distinguished: first, an illusion that God exists as the sum total of sensible realities, second, an illusion that God exists as the ground of the unity of the sensible world. Both are motivated by an interest of reason: the former by the need for the all of sensible realities by virtue 
of the PTD, the latter by the need for a ground of unity by virtue of reason's interest in systematic unity. However, only the second illusion is of regulative use for reason. ${ }^{56}$

\section{Conclusion}

In this article, I have taken issue with the widely held view that the possibility proof in Kant's pre-Critical Beweisgrund somehow survives in the form of the transcendental illusion that he exposes in section two of the Ideal. However, this illusion bears important differences to the possibility proof. The illusion seeks to establish a Spinozistic God and is motivated not by the need for an absolutely necessary being to ground possibility, but by the need for supplying conceptual content for the thoroughgoing determination of a thing. The much neglected proof a posteriori from Beweisgrund, on the contrary, anticipates the physico-theological proof, which in turn gives rise to a different transcendental illusion, according to which God must be the ground of the order of the world.

Let us return to the passage quoted from Th-Pölitz that we considered at the beginning. We can now see that the account in this transcript differs markedly from the Critique. For the transcript reads that all things 'presuppose a being that contains all realities in itself and that through the limitation of these realities must have constituted these things', which the transcript identifies with the 'ground of proof' exhibited in Beweisgrund (28: I034). But this depiction of the possibility proof is clearly incorrect. ${ }^{57}$ The proof argues that the highest being is the real ground of worldly realities, but has nothing to say about limitation. Nor does the quotation from the transcript agree with the Critique. There, Kant distinguishes between the grounding relation by which the totality of sensible realities makes the limitation of sensible concepts possible and the grounding relation by which God grounds worldly possibilities. Since students' notes are at least somewhat unreliable, we should not take for granted that Kant speaks so highly about the possibility proof unless the evidence from Th-Pölitz can be corroborated by other sources. But this is not the case. So we have to assume that the account in this transcript is an inadequate representation of Kant's view..$^{8}$

It is perhaps an unfortunate result that this leaves us without an explanation why Kant abandoned the possibility proof in the Critique. But there is no reason why he should give an account of it. What we should expect, on the contrary, is an explanation why Kant holds that the possibility 
proof is not only wrong, but not even a proof of God. But since Kant should have given such an account even if he had transformed the proof into a transcendental illusion, competing interpretations face the same problem. I have not investigated the fate of the possibility proof, but only argued that the proof does not survive in any form in the Critique. ${ }^{59}$

\section{Notes}

I See OPA, 2: 79-80, 83. As is customary, I quote from Kant according to volume and page numbers of the Akademie edition; the Critique of Pure Reason, however, is quoted according to the pagination of the $\mathrm{A}$ and $\mathrm{B}$ edition. Translations are from the Cambridge Edition of the Works of Immanuel Kant, although I have often amended them. The following abbreviations are used: CPJ = Critique of the Power of Judgement, $\operatorname{CPr} R=$ Critique of Practical Reason, Met-Dohna = Metaphysics Dohna, Met-K $\mathrm{K}_{2}=$ Metaphysics $\mathrm{K}_{2}$, Met-Mrong = Metaphysics Mrongovius, Met-Volckmann = Metaphysics Volckmann, OPA $=$ The Only Possible Ground of Proof, PM $=$ On the Progress of Metaphysics, Refl $=$ Reflexion, RPT $=$ On a Recently Raised Tone of Superiority, Th-Mron = Rational Theology Mrongovius, Th-Pölitz = Rational Theology Pölitz, Th-Volckmann = Rational Theology Volckmann.

2 See A625/B653 and A630/B658, also Abaci 2019: 208, n. I.

3 For an exception see Henrich I960: I48.

4 See also Th-Mron 28: I 260-I, and the references assembled by Chignell (2009: I 59-60) and Abaci (20I7: 270-I; 20I9: 2I 2, n. II). Chignell even holds that one relatively late Reflexion explicitly claims that the possibility proof 'proves' the existence of God: 'Reflexion 6278 (which is from as late as 1788 ) puts it even more categorically: "The possibility of things, which can only be regarded as determinations of a single universal possibility, namely of the highest being, proves the existence of the realissimi as a sum total [of realities]" (XVIII: 545)' (Chignell 2009: I 59, n. 7). But this reading is mistaken because the verb 'proves' is not a success term here, but equivalent to 'argues' - like the noun in, say, 'ontological proof', which likewise does not mean that God's existence can be proved by this argument. So the Reflexion does not show that Kant takes this argument to be successful. See also note 38 below.

5 See Chignell 2009: I 59, Stang 20I6: 26I, Abaci 20I7: 270; 20I9: 2II.

6 See Wood I978: 74, 76; Fisher and Watkins 1998: 390, 393-4; Grier 200I: 249; Abaci 20I7: 262, 270-2; 20I9: 209, 2I 8. The details of their account differ significantly, though. For a comprehensive overview of the literature see Abaci 2017: 262, n. 4; 20I9: 209, n. 3. Chignell (2009: I 59-60, I90-I) and Stang (2016: 262, 290, 296) even claim that, in addition to the regulative function, the proof shows the subjective necessity of belief (Glaube) in God. Thus, they hold that the possibility proof is basically still a valid argument, but the mode of holding-for-true is belief instead of knowledge. Space restrictions prevent me from engaging with their view in detail, but see note 55 .

7 The only somewhat detailed discussions of the proof I am aware of are in Schmucker I980: I07-35; Theis I994: III-35; Kanterian 201 8: 24I-63. See also Hoffer 2019, who rightly emphasizes the continuity between the proof a posteriori and the regulative use of reason in the Critique.

8 Kant briefly talks about two more proofs that he rejects, namely those that he later refers to as the 'ontological' and the 'cosmological' proof. See OPA, 2: $156 \mathrm{ff}$. , as well as Theis I994: I35-43 and Kanterian 201 8: 263-8 for helpful discussion.

9 For detailed discussion of the possibility proof, see Schmucker I980: 62-106; Wood I978: 64-7I; Fisher and Watkins I998: 369-80; Schönfeld 2000: I97-208; 
Chignell 2009; Stang 20I0; 20I6: chs 4-5; Boehm 20I4: 20-43; Kanterian 2018: 207-4I; Abaci: 20I9: 104-3I.

Io Boehm (20I4) holds that Kant indeed has a Spinozistic conception of God, whereas Chignell (20I2) claims that Spinozism is unavoidable (even in the Critical period), although Kant does not in fact accept this conception of God.

II For a more detailed defence of this view, see Yong 20I4: 30-8; Hoffer 20I6: I 89-93; Stang 2016: IO7-I2.

I2 It is not easy to understand the relation of the first two sections of Beweisgrund to each other. On the one hand, Kant says that the first section presents 'the ground of proof itself', whereas the second depicts 'the extensive use of it' (OPA, 2: 69). This may give the impression that the proof a posteriori is not independent of the possibility proof. On the other hand, Kant explicitly distinguishes these proofs in the third section of Beweisgrund (OPA, 2: I 59-6I). I take it that, since only the possibility proof is suitable for a strict demonstration, the second section depicts the use of the possibility proof insofar as only this proof can strictly establish the existence of God as the Wise Author of nature (which is needed for the purpose of laying the foundations for an improved method of physico-theology). Nevertheless, the second section also presents a proof different from the possibility proof.

I3 Compare OPA, 2: 155-6, with Met-Mron, 29: 748. Since the laws of geometry are grounded by God, they can belong to the basis of a proof a posteriori without being empirical. By presenting proofs a priori and a posteriori of God's existence, Kant follows the tradition of Wolff and others (see Abaci 2019: 60).

I4 As Hoffer (2016: I94) points out, Kant appears to use 'essence' and 'internal possibility' interchangeably in Beweisgrund.

I5 The referent of 'it' (desselben) is of itself unclear, but the context ensures that Kant is speaking about God.

I6 See also OPA, 2: I62, and Theis I994: I4I; Kanterian 20I 8: I67-8.

I7 See Wood I978: 5I-9; Longuenesse I998: 296-7; 2005: 2I4-23; Grier 200I: 234-45; Allison 2004: 396-405; Abaci 20I7: 274-6; 20I9: 2I 5-I7; Willaschek 20I8: 2I8-3I; also my 20I 8: 89-94.

I8 Some concepts contain covert transcendental negations: < being blind> means the absence of the sense of seeing (which is a reality), so it actually means: <being nonseeing $>$. See $\mathrm{A}_{575} / \mathrm{B} 603$.

I9 See RPT 8: 400-In., also PM (and lose Blätter), 20: 303, 330, 350-I, Met-Volckmann, 28: 457, Met-Dohna, 28: 692-3, Met-K 2 , 28: 779-82, Th-Mron, 28: I265-6.

20 See Grier 200I: 242; Allison 2004: 403-4; Longuenesse 2005: 222; Stang 2016: 274, n. 25 ; Abaci 20I7: 276-7; 20I9: 2I7. However, these authors do not note that this claim amounts to a distinction between an illegitimate and a legitimate conception of God, probably because Kant does not explicitly distinguish between these conceptions in the Ideal.

2 I This does not mean that the ens realissimum in the illegitimate sense cannot also be the ground of possibility (see note 44 ). But this would not free God from limitations, so the concept remains illegitimate even then.

22 See CPJ, 5: 439-40, Met-Volckmann, 28: 457-9, Met-Dohna, 28: 693-4, 698.

23 See Wood I978: $3 \mathrm{I}-3$.

24 See also Refl 6259, I 8: 534, Met-Volckmann, 28: 42I, Th-Volckmann, 28: I I68, Th-Mron, 28: I250. Kant's claim that there cannot be pure realities in the world is ambitious and he argues for this view mainly in his lectures. The general idea is that the world of sense has the forms of space and time, and all realities that occur in space and time must be limited. See RPT, 8: 40on., Met- $\mathrm{K}_{2}$, 28: 779-82, Th-Volckmann, 28: II62-5, Th-Mron, 28: I254. 
25 See A602/B630. I discuss this issue at length in my 2018.

26 See Henrich I960: I42-4; Longuenesse I998: 526-7; Grier 200I: 248; Allison 2004: 404; Abaci 2017: 276-9; 2019: 228.

27 See Wood I978: 37-4I for helpful discussion. As should be clear, this notion has its origin in Leibniz.

28 Granted, Kant does not make this (plausible) premise explicit, but it is needed to make the argument work. Otherwise, the whole of limited concepts would presuppose some unlimited realities, but not all of them, and hence not the whole concept of God.

29 Although Kant does not make it clear, I assume that limitation is still a conceptual and not a metaphysical relation.

30 Strictly speaking, God's complete consequences also include noumenal realities, but these can be neglected here because they are not epistemically accessible to us.

3 I I criticized Kant for what I took to be his derivation of sensible from divine realities in my 20I 8: 98-100 and argued that this is impossible if, as he holds, sensible realities are essentially spatiotemporal. Now I realize that Kant's view that we must derive sensible concepts from the complete consequences of God may be an attempt to avoid this problem. Still, it is not clear that the conception of an all of sensible realities is coherent if sensible realities cannot be separated from negations.

32 Guyer and Wood translate diese as 'these possibilities', but grammatically the demonstrative could refer either to 'all possibility of the things' or to 'the highest reality'. To my mind, the second reading makes more sense because it fits better the series of illusions, as presented below.

33 See Grier 200I: II7-30, in particular I 28-9, also Abaci 20I7: 272-4; 20I9: 2I3-I4.

34 See A58 I-3/B609-I I. For more detailed discussion, see Grier 200I: 245-8; Stang 20I6: 288-95; Abaci 2017: 279-87; 2019: 210-26.

35 I take it that Kant is making a transition here from determining a complete concept with regard to all possible realities to determining it with regard to all possible sensible realities. This seems to be part of the illusion that the all of sensible realities is the all of realities in general (see below). A question that Kant does not even seem to raise, though, would be what the all of sensible reality consists in, given that no sensible predicate is purely positive (see note $3 \mathrm{I}$ ).

36 This is why Kant refers back to the Transcendental Analytic (see A58I/B609). There (that is, in the Postulates), he argues that we can become acquainted with the matter of possibility only by experience (see A222/B269-70). See Abaci 20I7: 282; 20I9: 22I.

37 As regards the fact that there is this illusion, I agree with Grier 200I: 246-7; Stang 20I6: 29I-2; and Abaci 20I7: 283-4; 20I9: 22I; although their reasoning differs from mine.

38 It is for this reason that Kant writes in Refl 6278, 'The possibility of things, which can only be regarded as determinations of a single universal possibility, namely of the highest being, proves the existence of the realissimi as a sum total.' ( $18: 545$, n. 3 ). Kant considers the possibilities of things as limitations (or 'determinations', which in this context comes to the same) of the sum total of realities because the realities that some worldly thing instantiates are a subset of the all of sensible realities. However, the proof is unsuccessful because the latter is demanded by reason, but cannot be fully instantiated.

39 See $\mathrm{A}_{5} 82 / \mathrm{B} 610$. It is only here that Kant uses the term 'natural illusion'. I extend the use of it to the whole series of missteps of reason that he discusses in section two.

40 Again, it must be noted that the idea of the all of sensible reality may be incoherent; and it is unclear whether the totality of positive sensible concepts is actually different from the totality of sensible concepts. See notes 3 I and 35 .

4I As we shall see later, this is the view held by some readers. 
42 Kant makes these illusions more explicit in a later section. He calls the first illusion an 'entirely natural (though not for this reason secure) inference' (A6I5/B643) and the second a 'dialectical but natural illusion' (A6I5/B643).

43 See Grier 200I: 233-4, 252-3; Allison 2004: 405; Abaci 20I7: 288-9; 20I9: 226. Willaschek, on the contrary, agrees with me that 'the function of Section Three' is 'to prepare the discussion of the three proofs of God's existence' (Willaschek 20I8: 23I, n. 22), but does not seem to distinguish between a legitimate and an illegitimate conception of God (225-3 I, similarly Henrich I960: I49-50). This apparently makes him think that the illusion in section two is just part of the formation of the concept of God, without resulting in a transcendental error (see Willaschek 20I8: 23I, n. 22).

44 On Allison's view, the 'first [illusion treats] the how or what we might term the mechanism of hypostatization and the second the why or the motivation for it' (Allison 2004: 405 , see also 4IO-I2). But this wrongly presupposes that these illusions deal with the same conception of God. Abaci holds that the natural course of reason adds the illusion that sensible realities are grounded by God to the illusion that these realities are God (see Abaci 20I7: 288-9; 20I9: 226-8). But if these illusions belong together, then this would mean that God grounds himself, which is clearly not Kant's intention. I am less sure about Grier's view, but I take it that she thinks that the sum total is also the ground of reality, according to the illusion (see Grier 200I: 252). But this reading is impossible: although the last step of the natural illusion in section two makes God into an intelligence that grounds the unity of appearances (see A583/B6IIn. and Grier 200I: 234), this would be an unacceptable reading of section three because it would leave us without a consistent concept of God.

45 Grier worries that there would be 'no one clearly defined idea' of God in this case (200I: 233). But since Kant considers only one idea legitimate, I do not see the problem.

46 See Chignell 2009: $\mathrm{I}_{60-3}$, who makes this point with regard to Kant's use of the term in Beweisgrund.

47 Again, we have to distinguish between dialectical illusions and dialectical errors. The illusions that there must be an absolutely necessary being and that this being is the most real being are not yet errors. I take it that the natural course of reason is a series of errors that happens when we fall prey to the illusions. Nonetheless, the natural course is best understood not as a proof itself, but as the psychological process of adopting these dialectical views.

48 Importantly, Kant is speaking about a harmony in, or between, 'natures'; this suggests that he has a non-moral order in mind. This reading will get further support in the discussion to follow.

49 See A625-6/B653-4. The physico-theological proof is rarely discussed in the literature, but see Wood I978: I30-2, I37-4I, and Pasternack 20IIa: 4I2-I6, with whose accounts I generally agree.

50 This is opposed to the contingent arrangement of matter, which merely concerns the form. Thanks to an anonymous referee for pressing me on this.

5I To be sure, Kant does not make explicit that he is beginning to discuss a second argument, so one might doubt that there are in fact two different arguments. However, if there were just one argument, Kant could have stopped the discussion when he established that the physico-theological proof could at best prove the existence of a world architect; the rest of the discussion would be redundant at best and inconsistent at worst.

52 I largely follow Grier's insightful reading of the regulative use of reason in this section (see Grier 200I: ch. 8, especially 279-88, 294-30I, also Stang 20I6: 288-96). For accounts of the connection between the regulative use of reason and God's grounding 
of possibility that are similar to mine, see Wood I978: I4I-5; Grier 200I: 294-30I; Chignell 2007: 345-50; Pasternack 20IIa: 420-I; 20IIb: 2IO-I5; Stang 20I6: 28 5-6, 288, 29I; Abaci 20I7: 284; Hoffer 2019.

53 See A644/B672, A664-6/B692-4, A671/B699. Kant explains the difference between 'constitutive' and 'regulative' principles in Ar79-80/B22 Iff.

54 To be sure, this raises the question why this unity is impossible in experience, which I cannot address here.

55 As mentioned in note 6, Chignell and Stang think that the demands of reason justify not only the regulative use of the idea of God, but even belief in God in the specific Kantian sense. This is true for the first Critique, but wrong for the third. In the first Critique, Kant holds that the regulative use of reason justifies what he calls 'doctrinal belief' (A824/B853; Kant discusses doctrinal belief in A826-7/B854-5). But in later work, the notion of 'doctrinal belief' not only disappears (see CPJ, 5:467-74, RPT 8: 396-7n.), Kant even states that the great unity and harmony of the world does not justify Belief because the existence of a creator would only be 'the most adequate opinion and hypothesis for our reason' (CPJ, 5: 470). The 'principles of speculative reason' are merely 'regulative' because they 'do not impose [speculative reason] to assume a new object above experience, but only to approximate the use of reason in experience to completeness' ( $C P r R, 5:$ I 35$)$. So Kant's new view is that the regulative use of reason does not justify belief of any sort.

56 To be sure, Kant says that the PTD 'prescribes to the understanding the rule of its complete use' (A A73/B60I , which shows that it has a legitimate, regulative use (see also Willaschek 20I 8: 222). But the flawed conception of God discussed in section two is only achieved after a series of illusions of which the PTD is only the first step; and this series as a whole is of no regulative use.

57 Furthermore, the transcript blurs the difference between the possibility proof and the proof a posteriori (see Th-Pölitz, 28: I034-5).

58 This should not come as a surprise, though. It must have been even more difficult for Kant's listeners to distinguish the different argumentative threads than it is for his readers; and he may also have been less precise when he talked about his account than in writing.

59 For helpful comments, I would like to thank the participants of a colloquium meeting in 2018 at Humboldt University of Berlin led by Reed Winegar, as well as several referees for this journal. I am also grateful for the feedback I received when I presented my initial ideas to Rosalind Chaplin, Joe Stratmann and Eric Watkins.

\section{References}

Abaci, Uygar (20I7) 'Kant, the Actualist Principle, and the Fate of the Only Possible Proof'. Journal of the History of Philosophy, 55, 26I-9I.

- (2019) Kant's Revolutionary Theory of Modality. Oxford: Oxford University Press.

Allison, Henry E. (2004) Kant's Transcendental Idealism: An Interpretation and Defense. Revised and enlarged edition. New Haven, CT: Yale University Press.

Boehm, Omri (2014) Kant's Critique of Spinoza. Oxford: Oxford University Press. Chignell, Andrew (2007) 'Belief in Kant'. Philosophical Review, I I6, 323-60.

- (2009) 'Kant, Modality, and the Most Real Being'. Archiv für Geschichte der Philosophie, 91, I 57-92.

- (20I2) 'Kant, Real Possibility, and the Threat of Spinoza'. Mind, I 2 I, 635-75.

Fisher, Mark, and Eric Watkins (1998) 'Kant on the Material Ground of Possibility: From "The Only Possible Argument" to the "Critique of Pure Reason"'. Review of Metaphysics, 52, 369-95. 
Grier, Michelle (200I) Kant's Doctrine of Transcendental Illusion. Cambridge: Cambridge University Press.

Henrich, Dieter (1960) Der ontologische Gottesbeweis: Sein Problem und seine Geschichte in der Neuzeit. Tübingen: J. C. B. Mohr.

Hoffer, Noam (2016) 'The Relation between God and the World in the Pre-Critical Kant: Was Kant a Spinozist?' Kantian Review, 2I, I8 5-2 I0.

_ (2019) 'Kant's Regulative Metaphysics of God and the Systematic Lawfulness of Nature'. Southern Journal of Philosophy, 57, 217-39.

Kanterian, Edward (2018) Kant, God and Metaphysics: The Secret Thorn. London: Routledge.

Longuenesse, Béatrice (1998) Kant and the Capacity to Judge: Sensibility and Discursivity in the Transcendental Analytic of the Critique of Pure Reason. Princeton, NJ: Princeton University Press.

- (2005) 'The Transcendental Ideal and the Unity of the Critical System'. In Kant on the Human Standpoint (Cambridge: Cambridge University Press), 2 I I-35.

Oberst, Michael (2018) 'Kant on Contradiction, Conceptual Content, and the Ens Realissimum'. Kant Yearbook, Io, 85-103.

Pasternack, Lawrence (20I Ia) 'Regulative Principles and "the Wise Author of Nature". Religious Studies, 47, 4I I-29.

— (20I Ib) 'Kant's Doctrinal Belief in God'. In Oliver Thorndike (ed.), Rethinking Kant, vol. 3 (Newcastle upon Tyne: Cambridge Scholars Publishing), 200-I 8.

Schmucker, Josef (1980) Die Ontotheologie des vorkritischen Kant. Berlin: de Gruyter.

Schönfeld, Martin (2000) The Philosophy of the Young Kant: The Precritical Project. Oxford: Oxford University Press.

Stang, Nicholas (2010) 'Kant's Possibility Proof'. History of Philosophy Quarterly, 27, $275-99$.

- (2016) Kant's Modal Metaphysics. Oxford: Oxford University Press.

Theis, Robert (I994) Gott: Untersuchung der Entwicklung des theologischen Diskurses in Kants Schriften zur theoretischen Philosophie bis hin zum Erscheinen der Kritik der reinen Vernunft. Stuttgart: fromann-holzboog.

Willaschek, Marcus (2018) Kant on the Sources of Metaphysics: The Dialectic of Pure Reason. Cambridge: Cambridge University Press.

Wood, Allen (1978) Kant's Rational Theology. Ithaca, NY: Cornell University Press.

Yong, Peter (2014) 'God, Totality and Possibility in Kant's Only Possible Argument'.

Kantian Review, I9, 27-5I. 